\title{
Thermally stable polymer-ceramic composites for microwave antenna applications
}

\author{
Li ZHANG, Jie ZHANG, Zhenxing YUE*, Longtu LI \\ State Key Laboratory of New Ceramics and Fine Processing, School of Materials Science and Engineering, \\ Tsinghua University, Beijing100084, China
}

Received: May 19, 2016; Revised: July 12, 2016; Accepted: July 15, 2016

(C) The Author(s) 2016. This article is published with open access at Springerlink.com

\begin{abstract}
Polymer-ceramic composites were prepared by twin screw melt extrusion with high-density polyethylene (HDPE) as the matrix and polystyrene-coated $\mathrm{BaO}-\mathrm{Nd}_{2} \mathrm{O}_{3}-\mathrm{TiO}_{2}$ (BNT) ceramics as the filling material. Interestingly, the incorporation of polystyrene (PS) by the coating route could significantly improve the thermal behaviors of the composites (HDPE-PS/BNT), besides the temperature stability of dielectric properties and thermal displacement. The microwave dielectric properties of the composites were investigated systematically. The results indicated that, as the volume fraction of BNT ceramic particles increased from 10 to $50 \mathrm{vol} \%$ in the composites, the dielectric constant increased from $3.54(9.23 \mathrm{GHz})$ to $13.14(7.20 \mathrm{GHz})$, which can be beneficial for the miniaturization of microwave devices; the dielectric loss tangent was relatively low $(0.0003-$ 0.0012); more importantly, the ratio of PS to HDPE increased accordingly, making the composite containing $50 \mathrm{vol} \%$ BNT ceramics have a low value of temperature coefficient of resonant frequency $\left(\tau_{f}=-11.2 \mathrm{ppm} /{ }^{\circ} \mathrm{C}\right.$ ) from -20 to $60{ }^{\circ} \mathrm{C}$. The GPS microstrip antennas were therefore designed and prepared from the HDPE-PS/BNT composites. They possessed good thermal stability $\left(\tau_{f}=\right.$ $23.6 \mathrm{ppm} /{ }^{\circ} \mathrm{C}$ ) over a temperature range of -20 to $60{ }^{\circ} \mathrm{C}$, promising to meet the requirements of practical antenna applications.
\end{abstract}

Keywords: polymer-ceramic composites; microwave dielectric properties; thermal stability; GPS antenna

\section{Introduction}

For the practical use of antennas at high frequencies, dielectric materials are required to have a high dielectric constant $\left(\varepsilon_{\mathrm{r}}\right)$ for miniaturization, a low dielectric loss $(\tan \delta$ ) to facilitate the signal integrity, and a near-zero temperature coefficient of resonant frequency $\left(\tau_{f}\right)$ against temperature change [1,2]. Currently,

\footnotetext{
* Corresponding author.

E-mail: yuezhx@mail.tsinghua.edu.cn
}

commercial microwave ceramics usually have $\varepsilon_{\mathrm{r}}$ of $10-120$, low $\tan \delta$, and near-zero $\tau_{f}$. However, they are fragile and need high sintering temperature, making the processing difficult and raising the cost $[3,4]$. Therefore, they have been only used in a few fields, such as antennas for vehicle mounted GPS, resonators for base station, electronic filters, and so on. Polymers, such as polytetrafluoroethene (PTFE) and high-density polyethylene (HDPE), have low dielectric loss, high flexibility, and simplified process. Also, they have been predominantly used for microwave packaging and 
substrates. Nevertheless, their low $\varepsilon_{\mathrm{r}}(<3$ at $10 \mathrm{GHz})$ limits the miniaturization for antennas. Polymerceramic composites of 0-3 connectivity have high $\varepsilon_{\mathrm{r}}$, low $\tan \delta$, and high elasticity; more importantly, they can be processed easily [5-8]. They have been widely used as commercial microwave substrates and mini-antennas, such as some products from Rogers and Taconic [9]. However, the values of the temperature coefficient of dielectric constant $\left(\tau_{\varepsilon_{\mathrm{r}}}\right)$ of polymer matrixes, such as PTFE and HDPE, are still very high. In fact, they are very sensitive to temperature change. So, directly compositing ceramics with such one type of composite matrixes (PTFE or HDPE) would make the materials have poor thermal stability $[10,11]$. The corresponding antennas cannot be used outdoor except extra temperature compensating circuits added, which greatly limits the applications of polymer-ceramic composites in the preparation of outdoor antennas.

Among the composite matrixes, both HDPE and polystyrene (PS) have excellent microwave dielectric properties, and more importantly, they exhibit opposite signs of $\tau_{\varepsilon_{r}}$. Thus, thermally stable composites could be achieved by using HDPE and PS together. Herein, Bi substituted $\mathrm{BNT}$ in $\mathrm{BaO}-\mathrm{Nd}_{2} \mathrm{O}_{3}-\mathrm{TiO}_{2}$ system was chosen as the ceramic filler because it has a high dielectric constant of 88 , a low dielectric loss of $<0.0005$, and a $\tau_{f}$ of $0 \pm 5 \mathrm{ppm} /{ }^{\circ} \mathrm{C}[12,13]$; while HDPE was selected as the basic matrix. Then, a coating route with the incorporation of polystyrene (PS) was designed to improve the thermal behaviors of the composites. Specifically, the BNT particles were coated with PS through the liquid phase coating process, and the PS-coated BNT ceramics were used as the filling material. The polymer-ceramic composites were prepared from PS-coated BNT ceramics and HDPE through twin screw melt extrusion. The as-prepared composites showed high dielectric constant, low dielectric loss, high thermal stability, and good mechanical property. They are beneficial for the use in RFID (radio frequency identification) antennas $(900 \mathrm{MHz}, 2.4 \mathrm{GHz})$, satellite navigation antennas for GPS and Compass $(1.575 \mathrm{GHz}, 1.268 \mathrm{GHz})$, wireless broadband antennas $(2.4 \mathrm{GHz}, 5.8 \mathrm{GHz})$, and so on.

\section{Experimental procedure}

Polymer-ceramic composites were prepared by the
PS-coated BNT ceramic particles, and followed by the twin screw melt extrusion with HDPE. Analytically pure $\mathrm{BaCO}_{3}, \mathrm{Nd}_{2} \mathrm{O}_{3}, \mathrm{TiO}_{2}$, and $\mathrm{Bi}_{2} \mathrm{O}_{3}$ (Chinese Medicine Group Chemical Reagent Co., Ltd.) were used as the raw materials to prepare BNT ceramics through conventional solid-state reaction route. Firstly, $\mathrm{BaCO}_{3}, \mathrm{Nd}_{2} \mathrm{O}_{3}, \mathrm{Bi}_{2} \mathrm{O}_{3}$, and $\mathrm{TiO}_{2}$ powder was weighed in stoichiometric proportion $\left(\mathrm{BaNd}_{1.76} \mathrm{Bi}_{0.24} \mathrm{Ti}_{5} \mathrm{O}_{14}\right)$ and then milled for $6 \mathrm{~h}$. The slurry was dried and calcined at $1100{ }^{\circ} \mathrm{C}$ for $3 \mathrm{~h}$. The calcined powder was finely ground, and sintered at $1280{ }^{\circ} \mathrm{C}$ for $4 \mathrm{~h}$. Then, the zirconia balls were used as grinding media and the ball to powder ratio was 15:1. The sintered powder was ground with a high energy ball mill for $30 \mathrm{~min}$ at $1500 \mathrm{rpm}$. After drying and sieving with a 120 mesh screen, the obtained BNT powder was then mixed with $2 \mathrm{wt} \%$ tetraethylbutane, and aged for $24 \mathrm{~h}$ to improve its compatibility with organic polymers. PS (DOW Chemical Co., USA) was dissolved in dimethylbenzene at $85{ }^{\circ} \mathrm{C}$. The prepared BNT powder was added to dimethylbenzene at $85{ }^{\circ} \mathrm{C}$, ultra-sonicated for $10 \mathrm{~min}$, and mixed with the PS solution. The mixture of PS and BNT was stirred at $85{ }^{\circ} \mathrm{C}$ for 20 min and evaporated at $120{ }^{\circ} \mathrm{C}$ to dryness, and then ground and sieved through a 60 mesh screen to obtain PS-coated BNT powder. To ensure the composites to have good formability and higher content of PS (to compensate $\tau_{f}$ for the composites), the volume ratio of PS to BNT was fixed to $4: 6$.

The HDPE/PS-coated BNT (HDPE-PS/BNT) composites were prepared from HDPE (LG Chemistry Co., R. O. Korea) and PS-coated BNT powder (10$50 \mathrm{vol} \%$ BNT) by conical twin-screw extruder (HAAKE MINICTW, Germany) at $180{ }^{\circ} \mathrm{C}$ with $30 \mathrm{rpm}$. Wafers with a diameter of $70 \mathrm{~mm}$ and a thickness of $1 \mathrm{~mm}$ were prepared by compressing the composites at $200 \mathrm{MPa}$ and $220{ }^{\circ} \mathrm{C}$ for $30 \mathrm{~min}$. They were polished for further use. The volume fraction of the individual ingredients in the HDPE-PS/BNT composites is listed in Table 1.

Table 1 Volume fraction of the individual ingredients in the HDPE-PS/BNT composites

\begin{tabular}{ccccc}
\hline & BNT (vol\%) & PS (vol\%) & HDPE (vol\%) & PS:HDPE \\
\hline 1 & 10 & 6.7 & 83.3 & $1: 12$ \\
2 & 20 & 13.3 & 66.7 & $1: 5$ \\
3 & 30 & 20.0 & 50.0 & $1: 2.5$ \\
4 & 40 & 26.7 & 33.3 & $1: 1.25$ \\
5 & 50 & 33.3 & 16.7 & $1: 0.5$ \\
\hline
\end{tabular}


The phase compositions of the prepared HDPEPS/BNT composites were characterized by X-ray diffraction (XRD) analysis with $\mathrm{Cu} \mathrm{K} \alpha$ radiation (Rigaku D/Max-2500, Tokyo, Japan). The morphologies of the composites were observed with a scanning electron microscope (SEM; JEOL-JSM 6301F, Tokyo, Japan). Their enthalpies of phase transition were measured with a differential scanning calorimeter (DSC; DSC200F3, Netzsch, Germany). The microwave dielectric properties of the composites were measured by split cylinder resonator method. The dielectric properties of the composites at $1 \mathrm{GHz}$ frequency were determined with an RF impedance/material analyzer (E4991A, Agilent, Santa Clara, CA, USA). The thermal expansion coefficients of the composites in the temperature range of $30-90{ }^{\circ} \mathrm{C}$ were measured with a thermomechanical analyzer (Dil402 PC, Netzsch, Germany). Density was measured by drainage method. The performances of the antennas prepared from the HDPE-PS/BNT composites were evaluated with a network analyzer (HP8720ES, Hewlett-Packard, Santa Rosa, CA, USA).

\section{Results and discussion}

Figure 1 shows the XRD patterns of the HDPEPS/BNT composites with $0,10,30,50$ vol\% BNT powder. It indicates that the sample with no BNT exhibits pure phase corresponding to HDPE. With BNT particles, the composites are mainly indexed to HDPE and $\mathrm{BaNd}_{2} \mathrm{Ti}_{5} \mathrm{O}_{14}$ phases, and the $\mathrm{BaNd}_{2} \mathrm{Ti}_{5} \mathrm{O}_{14}$ refraction peaks increase with the increasing $\mathrm{BNT}$ content.

The SEM images for backscattered electron of composites containing 10, 20,30, and $50 \mathrm{vol} \%$ BNT

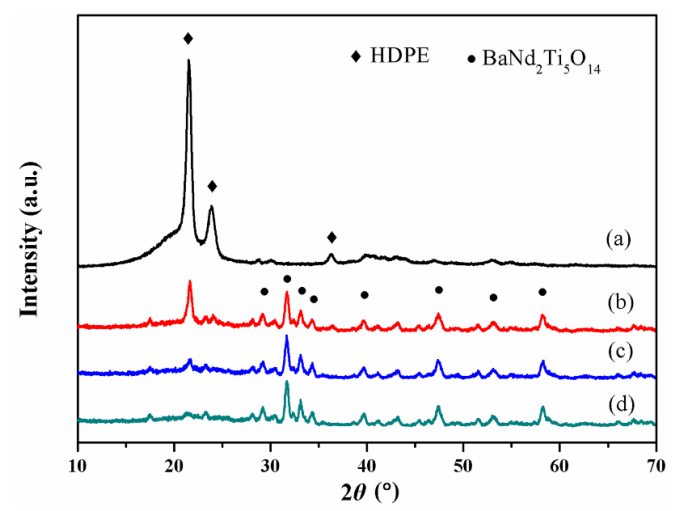

Fig. 1 XRD patterns of the HDPE-PS/BNT composites containing (a) 0, (b) 10, (c) 30, and (d) $50 \mathrm{vol} \%$ BNT. particles are shown in Fig. 2. It can be seen clearly that BNT particles with size of $0.5-3 \mu \mathrm{m}$ are uniformly distributed in the composites. HDPE and BNT are tightly combined with a clear interface, and any apparent pores cannot be observed, indicating a uniform microstructure of the composites. It indicates that the ultra-sonication processing and PS coating could effectively improve the dispersiveness of BNT particles into HDPE matrix. For example, as shown in the SEM images, the composite particles with size over $10 \mu \mathrm{m}$ are barely observed even in the composite containing 50 vol $\%$ BNT.

DSC analysis of endothermic and exothermic processes can be used to qualify and quantify the relationship between temperature and structural transition. PS is amorphous, and no crystallization and melting peaks can be observed in its DSC curve (Fig. 3), while the crystalline polymer HDPE shows an endothermic peak at $132.5{ }^{\circ} \mathrm{C}$. The HDPE-PS/BNT composites containing 10,30 , and $50 \mathrm{vol} \%$ BNT also show endothermic peaks at such equivalent temperature, and the intensity of the endothermic peaks decreases with the increase of BNT content. This implies that the crystalline behavior of HDPE cannot be largely influenced by the ceramic particles or PS phase.

Table 2 lists the experimental and calculated enthalpies of fusion for the HDPE-PS/BNT composites containing different amounts of BNT. The calculated results can be obtained by multiplying the HDPE weight fraction in the HDPE-PS/BNT composites by $183.1 \mathrm{~J} / \mathrm{g}$ that is the experimental enthalpy of pure HDPE. It shows that the experimental results are well consistent with the calculated ones. These results indicate that the composites maintain good crystalline of HDPE, and they primarily consist of two phases with HDPE as the matrix and PS mainly coated on the surfaces of BNT particles.

Figure 4 shows the experimental and calculated dielectric constants of HDPE-PS/BNT composites at about $10 \mathrm{GHz}$. Here, Lichtenecker equation (Eq. (1)) and the effective medium theory (EMT, $n=1.6$, Eq. (2)) model are used to calculate the dielectric constants of HDPE-PS/BNT composites. The corresponding equations are given as follows:

$$
\begin{aligned}
& \log \varepsilon_{\mathrm{c}}=v_{\mathrm{f}} \log \varepsilon_{\mathrm{f}}+v_{\mathrm{m}} \log \varepsilon_{\mathrm{m}} \\
& \varepsilon_{\mathrm{c}}=\varepsilon_{\mathrm{m}}\left[1+\frac{v_{\mathrm{f}}\left(\varepsilon_{\mathrm{f}}-\varepsilon_{\mathrm{m}}\right)}{\varepsilon_{\mathrm{m}}+n v_{\mathrm{m}}\left(\varepsilon_{\mathrm{f}}-\varepsilon_{\mathrm{m}}\right)}\right]
\end{aligned}
$$

where $\varepsilon_{\mathrm{c}}, \varepsilon_{\mathrm{f}}$, and $\varepsilon_{\mathrm{m}}$ are the dielectric constants of 


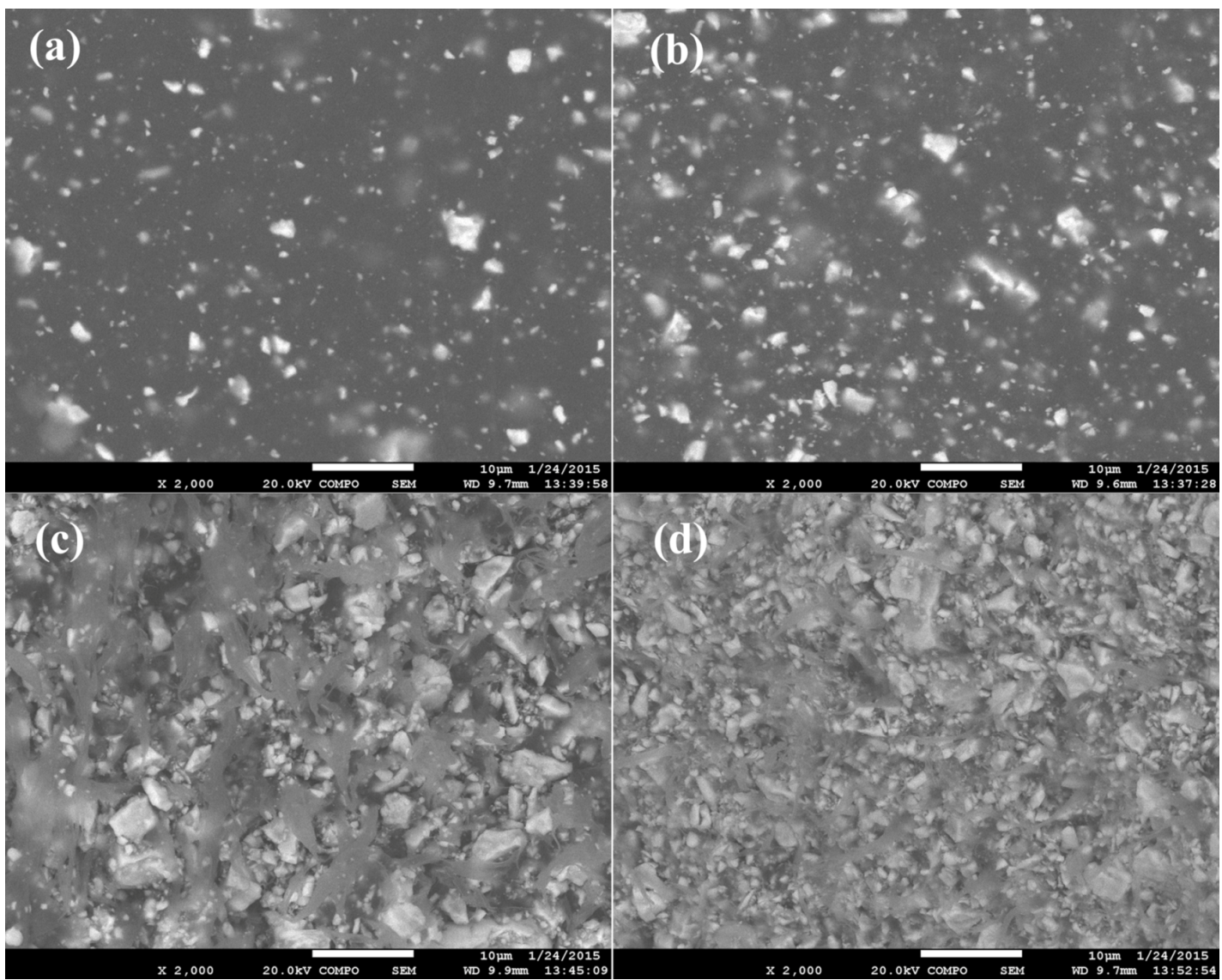

Fig. 2 SEM images of the HDPE-PS/BNT composites containing (a) 10, (b) 20, (c) 30, and (d) 50 vol\% BNT.

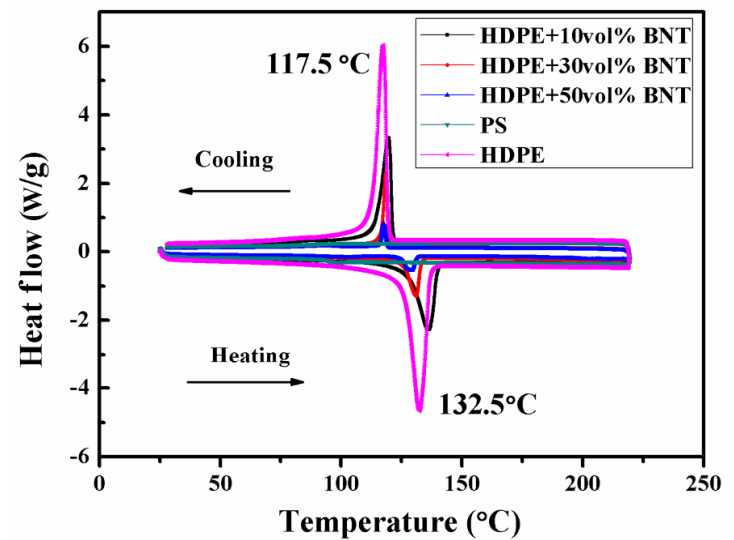

Fig. 3 DSC curves of HDPE, PS, and HDPE-PS/BNT composites containing 10,30, and $50 \mathrm{vol} \% \mathrm{BNT}$.

Table 2 Experimental and calculated enthalpies of fusion of HDPE, PS, and the HDPE-PS/BNT composites containing 10, 30, and 50 vol\% BNT (Unit: $\mathrm{J} / \mathrm{g}$ )

\begin{tabular}{cccccc}
\hline & HDPE & $10 \mathrm{vol} \%$ BNT & $30 \mathrm{vol} \%$ BNT & 50 vol\% BNT & PS \\
\hline Experimental & 183.1 & 100.6 & 32.1 & 9.7 & 0 \\
Calculated & 183.1 & 100.7 & 36.2 & 8.5 & 0 \\
\hline
\end{tabular}

the composites, BNT, and HDPE, respectively; $v_{\mathrm{f}}$ and $v_{\mathrm{m}}$ are the volume fractions of BNT and HDPE, respectively; $n$ is the correction factor to compensate for

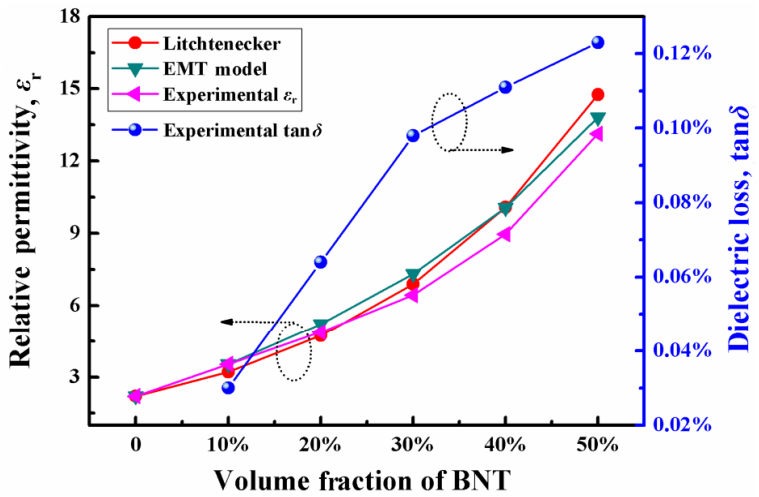

Fig. 4 Comparison of experimental dielectric constant with different theoretical model and variation of dielectric loss of HDPE-PS/BNT composites with different BNT volume fractions.

the shape of the fillers used in polymer-ceramic composites [1]. It is clear that the calculated results of the composites with low BNT contents are consistent with their corresponding experimental results. For the composites with high BNT contents, the calculated values are higher than their experimental results. It can be explained that, in those simulation models, the round ceramic particles are ideally suspected to distribute 
uniformly within the composites [14]. However, the aggregation is increased with the increase of BNT content, leading to the reduction of the interaction between polymer and BNT. So the inner structure of the composites is derived from the modeling structure. As the BNT fraction increases from 10 to $50 \mathrm{vol} \%$ (Fig. 4), the dielectric constants of the composites increase from $3.54(9.23 \mathrm{GHz})$ to $13.14(7.20 \mathrm{GHz})$, while the dielectric losses increase from 0.0003 to 0.0012 . As discussed above, the PS coating of BNT can improve the interaction between the polymer and BNT, and reduce deficiencies such as pores, resulting in a low dielectric loss. Therefore, the dielectric loss of the composites containing high amounts of BNT is still very low.

The relation between frequency and dielectric constant is one of the main aspects for the composites used in high frequencies. Figure 5 shows the variation of dielectric constant of the composites containing different amounts of BNT in the frequency range of $10 \mathrm{MHz}$ to $1 \mathrm{GHz}$. It can be clearly seen that the dielectric constants of all composites containing $10-50$ vol\% BNT almost remain sturdy within the ramping frequency, indicating that composites have stable frequency performance. These materials would have good applications in high frequencies.

Figure 6 shows the temperature dependence of dielectric constant of HDPE and PS at $1 \mathrm{GHz}$ over a temperature range of -40 to $100{ }^{\circ} \mathrm{C}$. At the initial ramping temperature of $-40{ }^{\circ} \mathrm{C}$, they possess similar dielectric constants. With the increase of temperature $\left(-20\right.$ to $\left.60{ }^{\circ} \mathrm{C}\right)$, HDPE and PS exhibit different temperature dependences: the dielectric constant of HDPE decreases, while that of PS increases. The $\tau_{\varepsilon_{\mathrm{r}}}$

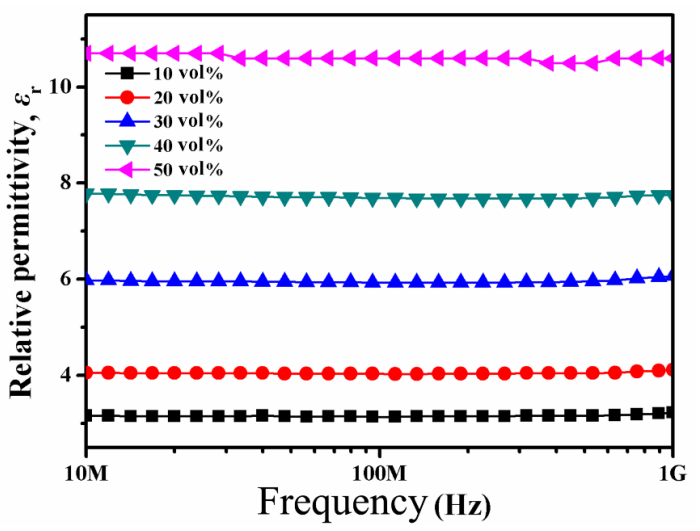

Fig. 5 Variation of dielectric constant of the composites containing different amounts of BNT in the frequency range of $10 \mathrm{MHz}$ to $1 \mathrm{GHz}$.

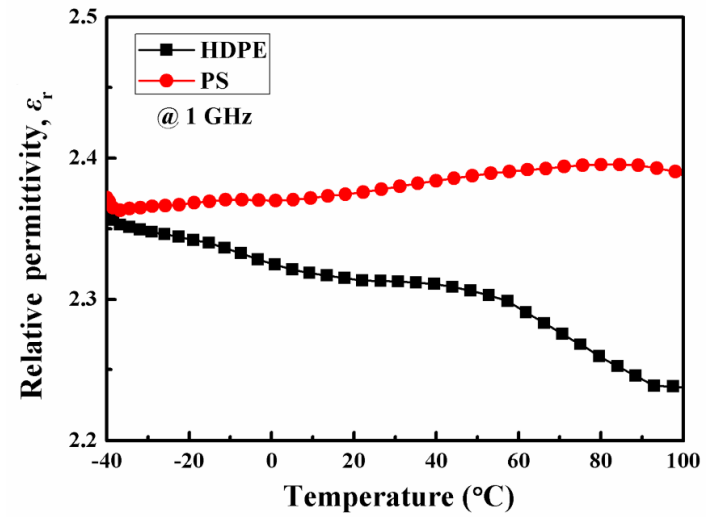

Fig. 6 Temperature-dependent dielectric constant of HDPE and PS at $1 \mathrm{GHz}$.

values of HDPE and PS are therefore determined to be $-278 \mathrm{ppm} /{ }^{\circ} \mathrm{C}$ and $124 \mathrm{ppm} /{ }^{\circ} \mathrm{C}$, respectively. With the increasing temperature, the polymers (HDPE) expand due to their high expansion coefficients. In fact, the number of the polarized groups per volume would be decreased as the expansion of the polymers, which could possibly induce the decrease of dielectric constant consequently. Thus, the dielectric constant of HDPE decreases with increasing temperature. The dielectric constants of PTFE and PP show similar changes with the increase of temperature. Although only limited free charges could be produced in PS backbone stimulated by the increasing temperature, a large amount of charge carriers would be induced by the impurity ionization and chemical bond breaking of its phenyl rings, leading to a high electron density. In addition, the phenyl rings can reduce the resistance to electron mobility, providing a channel for electron mobility. Therefore, the increase of the electric dipole moment caused by the phenyl rings suppresses its decrease with respect to the thermal expansion. The dielectric constant of PS mainly shows an increase with the increasing temperature. Also, the dielectric constant of epoxy has a similar relationship with temperature [15].

The temperature dependence of dielectric constant of substrate materials can significantly affect the performance of antennas. Figure 7 shows the variation of dielectric constant at $1 \mathrm{GHz}$ with temperature for the composites containing different amounts of BNT, over a temperature range of -40 to $160{ }^{\circ} \mathrm{C}$. As the BNT content increases from 10 to $50 \mathrm{vol} \%$, the dielectric constant of the composites remains stable at temperatures lower than $80{ }^{\circ} \mathrm{C}$. For example, the dielectric constant of the HDPE-PS/BNT composite containing 50 vol\% BNT 


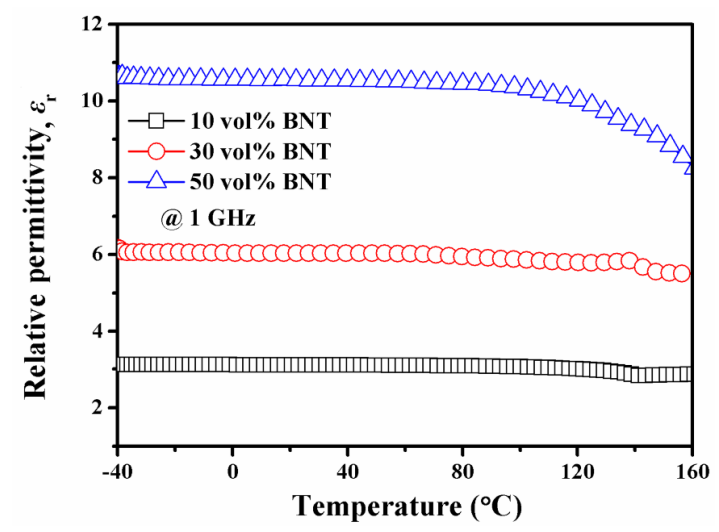

Fig. 7 Variation of dielectric constant for the composites with 10,30 , and $50 \mathrm{vol} \% \mathrm{BNT}$ at $1 \mathrm{GHz}$ over a temperature range of -40 to $160{ }^{\circ} \mathrm{C}$.

slightly decreases from 10.575 to 10.510 as the temperature increases from -20 to $60{ }^{\circ} \mathrm{C}$, resulting in a $\tau_{\varepsilon_{\mathrm{r}}}$ of $-76.8 \mathrm{ppm} /{ }^{\circ} \mathrm{C}$. These results indicate that the composites have better thermal stability than the conventional polymer-ceramic composites that usually have a very high temperature coefficient of dielectric constant. In addition, PS and HDPE, as the two independent phases, can complement each other in the temperature coefficient of dielectric constant.

Figure 8 shows the thermal displacement curves of PS and HDPE-PS/BNT composites over a temperature range of $30-90{ }^{\circ} \mathrm{C}$. It has been reported that the displacement of HDPE occurs at about $60{ }^{\circ} \mathrm{C}$; however, its melting point is as high as $130{ }^{\circ} \mathrm{C}$. This behavior can affect the thermal stability of HDPE/BNT composites. PS has a large phenyl ring backbone, which can avoid rotation and displacement at temperatures below its glass transition temperature. Therefore, PS has better mechanical property and strength. As shown in Fig. 8, the glass transition temperature of PS is at about $80{ }^{\circ} \mathrm{C}$.

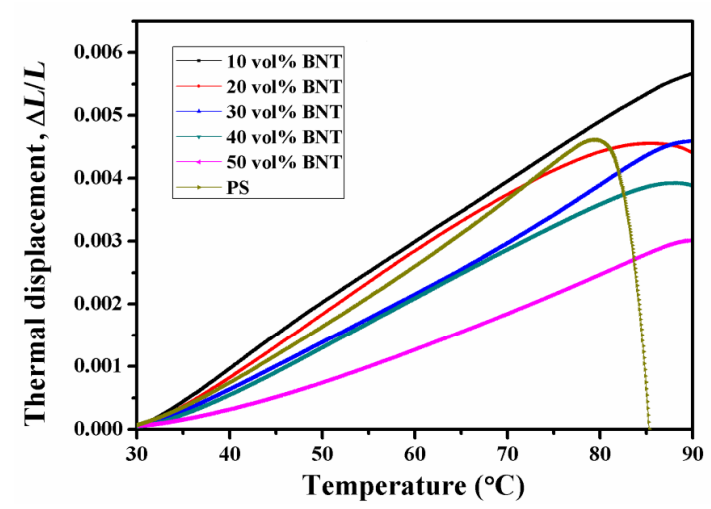

Fig. 8 Thermal displacement of the composites containing various amounts of BNT over a temperature range of $30-90{ }^{\circ} \mathrm{C}$.
Therefore, no displacement occurs to HDPE-PS/BNT composites at temperatures lower than $80{ }^{\circ} \mathrm{C}$. PS is located near the interfaces between ceramic particles and polymer. This configuration of interfaces can significantly affect the thermal properties of the composite materials. In addition, the thermal expansion coefficient of the composites decreases with the increase of BNT content, which is favorable to its thermal stability.

In general, for a substrate material used in antennas, the temperature coefficient of resonant frequency $\left(\tau_{f}\right)$ is the key factor for the thermal property of the devices. The $\tau_{f}$ value of a linear microwave dielectric material can be calculated with Eq. (3):

$$
\tau_{f}=-\left(\alpha_{\mathrm{L}}+\frac{\tau_{\varepsilon_{\mathrm{r}}}}{2}\right)
$$

where $\alpha_{\mathrm{L}}$ is the linear thermal expansion coefficient of the material. For the composite containing $50 \mathrm{vol} \%$ BNT shown in Fig. $6, \tau_{\varepsilon_{\mathrm{r}}}$ is $76.8 \mathrm{ppm} /{ }^{\circ} \mathrm{C}$ over a temperature range of -20 to $60{ }^{\circ} \mathrm{C}$. Its $\alpha_{\mathrm{L}}$ value is about $49.6 \mathrm{ppm} /{ }^{\circ} \mathrm{C}$ (Fig. 8). Therefore, using Eq. (3), the calculated $\tau_{f}$ is $-11.2 \mathrm{ppm} /{ }^{\circ} \mathrm{C}$, meeting the primary requirement of microwave antenna materials. The HDPE-PS/BNT composite containing $50 \mathrm{vol} \%$ BNT has a high dielectric constant and a small value of $\tau_{f}$, which can facilitate the miniaturization and thermal stability of antennas.

GPS microstrip antenna has been widely used due to its simple and low-cost fabrication process [16,17]. In order to demonstrate the feasibility of the as-prepared composites for antenna substrates, the GPS microstrip antennas were designed from the composite containing 50 vol\% BNT by Ansoft HFSS. The size of substrates used in antennas is $35 \mathrm{~mm} \times 35 \mathrm{~mm} \times 4 \mathrm{~mm}$ with two sides coated with $\mathrm{Cu}$ foil as the electrodes. Figure 9 shows the images of a prototype antenna, and the geometric dimensions of ground plane (a) and emitting surface (b) are also given. The $S_{11}$ curves of the designed GPS antenna were measured at different temperatures, and the results are shown in Fig. 10. The resonant frequency of the antenna at $20{ }^{\circ} \mathrm{C}$ (room temperature) is $1.591 \mathrm{GHz}$. As can be seen, the resonant frequency slightly changes from 1.590 to $1.593 \mathrm{GHz}$ as the temperature increases from -20 to $60{ }^{\circ} \mathrm{C}$, exhibiting excellent thermal stability. Its $\tau_{f}$ is $+23.6 \mathrm{ppm} /{ }^{\circ} \mathrm{C}$, meeting the requirement for antennas $\left(0 \pm 30 \mathrm{ppm} /{ }^{\circ} \mathrm{C}\right)$. The composite has good potential in the outdoor 

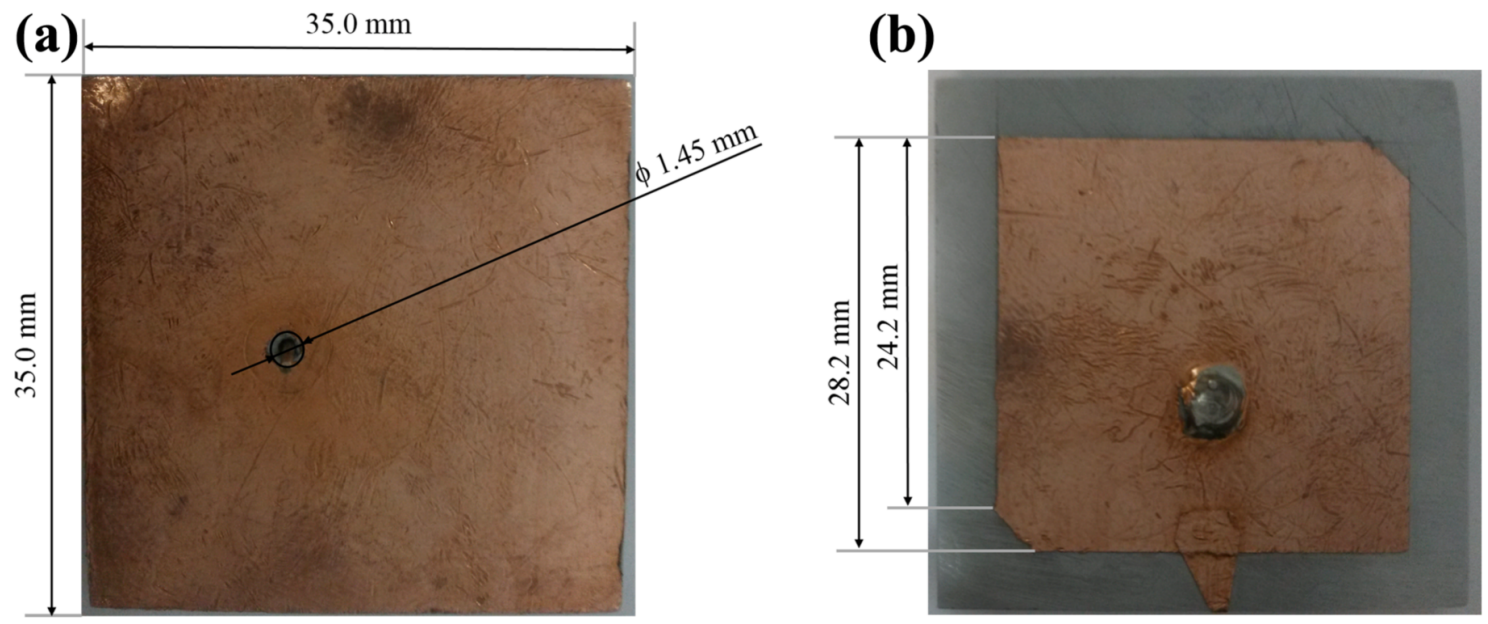

Fig. 9 (a) Ground plane and (b) emitting surface of the designed GPS antenna.

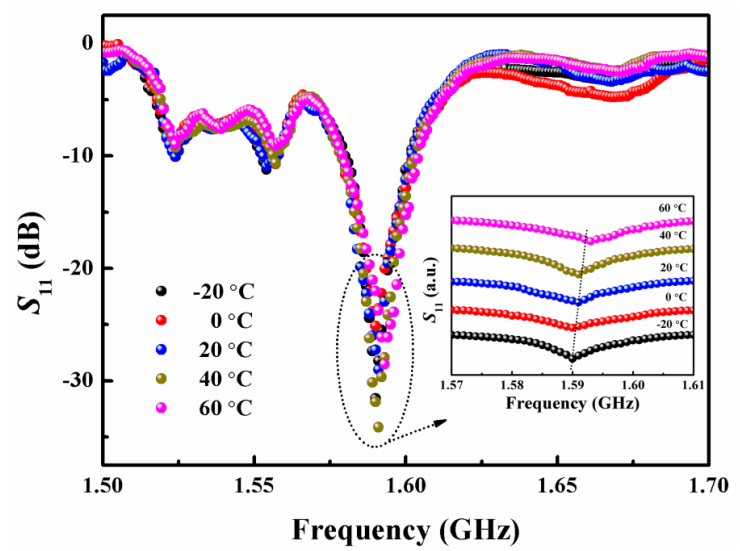

Fig. $10 \quad S_{11}$ curves of GPS antenna at different temperatures. The inset shows the details of resonant frequency.

environments without extra temperature compensating circuits added at various temperatures.

\section{Conclusions}

The twin screw extrusion of PS-coated BNT ceramic powder and HDPE improved the interfaces between the polymer and ceramics, which resulted in composites with high dielectric constant, low dielectric loss, and good thermal stability. The dielectric constant and dielectric loss of the HDPE-PS/BNT composite containing $50 \mathrm{vol} \% \mathrm{BNT}$ at $7 \mathrm{GHz}$ were 13.14 and 0.0012 , respectively. GPS antennas were prepared with the HDPE-PS/BNT composite containing $50 \mathrm{vol} \%$ $\mathrm{BNT}$ as the substrate. Its temperature coefficient of resonant frequency remained at $+23.6 \mathrm{ppm} /{ }^{\circ} \mathrm{C}$ over a temperature range of -20 to $60{ }^{\circ} \mathrm{C}$, meeting the requirements for outdoor antennas. The HDPE-
PS/BNT composites are temperature-stable with high relative permittivity. Also, they are easy to fabricate for promising candidates in the design of antennas.

\section{Acknowledgements}

This work is supported by the National Natural Science Foundation of China (Grant Nos. 51472138 and 51221291), the Ministry of Science and Technology of China through 973 Program under Grant No. 2015CB654605, and Tsinghua National Laboratory for Information Science and Technology (TNList) Cross-discipline Foundation.

\section{References}

[1] George S, Anjana PS, Sebastian MT, et al. Dielectric, mechanical, and thermal properties of low-permittivity polymer-ceramic composites for microelectronic applications. Int J Appl Ceram Tec 2010, 7: 461-474.

[2] Rajesh S, Murali KP, Ratheesh R. Preparation and characterization of high permittivity and low loss PTFE/ $\mathrm{CaTiO}_{3}$ microwave laminates. Polym Composite 2009, 30: 1480-1485.

[3] Ohsato $\mathrm{H}$, Ohhashi T, Kato H, et al. Microwave dielectric properties and structure of the $\mathrm{Ba}_{6-3 x} \mathrm{Sm}_{8+2 x} \mathrm{Ti}_{18} \mathrm{O}_{54}$ solid solutions. Jpn J Appl Phys 1995, 34: 187-191.

[4] Huang C-L, Wang J-J, Huang C-Y. Microwave dielectric properties of sintered alumina using nano-scaled powders of $\alpha$ alumina and $\mathrm{TiO}_{2}$. J Am Ceram Soc 2007, 90: 1487-1493.

[5] Subodh G, Joseph M, Mohanan P, et al. Low dielectric loss polytetrafluoroethylene $/ \mathrm{TeO}_{2}$ polymer ceramic composites. $J$ Am Ceram Soc 2007, 90: 3507-3511.

[6] James NK, Jacob KS, Murali KP, et al. $\mathrm{Ba}\left(\mathrm{Mg}_{1 / 3} \mathrm{Ta}_{2 / 3}\right) \mathrm{O}_{3}$ filled PTFE composites for microwave substrate applications. Mater Chem Phys 2010, 122: 507-511. 
[7] Thomas S, Deepu VN, Mohanan P, et al. Effect of filler content on the dielectric properties of $\mathrm{PTFE} / \mathrm{ZnAl}_{2} \mathrm{O}_{4}-\mathrm{TiO}_{2}$ composites. J Am Ceram Soc 2008, 91: 1971-1975.

[8] Subodh G, Deepu V, Mohanan P, et al. Polystyrene/ $\mathrm{Sr}_{2} \mathrm{Ce}_{2} \mathrm{Ti}_{5} \mathrm{O}_{15}$ composites with low dielectric loss for microwave substrate applications. Polym Eng Sci 2009, 49: 1218-1224.

[9] Sebastian MT, Jantunen H. Polymer-ceramic composites of 0-3 connectivity for circuits in electronics: A review. Int J Appl Ceram Tec 2010, 7: 415-434.

[10] Zhang L, Yue Z, Li L. Low dielectric loss polymer-ceramic composites for wireless temperature sensation. Key Engineering Materials 2014, 602-603: 752-756.

[11] Jacob KS, Satheesh R, Ratheesh R. Preparation and microwave characterization of $\mathrm{BaNd}_{2-x} \mathrm{Sm}_{x} \mathrm{Ti}_{4} \mathrm{O}_{12} \quad(0 \leqslant$ $x \leqslant 2$ ) ceramics and their effect on the temperature coefficient of dielectric constant in polytetrafluoroethylene composites. Mater Res Bull 2009, 44: 2022-2026.

[12] $\mathrm{Wu} Y J$, Chen XM. Structures and microwave dielectric properties of $\mathrm{Ba}_{6-3 x}\left(\mathrm{Nd}, \mathrm{Bi}_{\mathrm{y}}\right)_{8+2 x} \mathrm{Ti}_{18} \mathrm{O}_{54} \quad(x=2 / 3)$ solid solution. J Mater Res 2001, 16: 1734-1738.

[13] Okawa $T$, Imaeda $M$, Ohsato $H$. Microwave dielectric properties of $\mathrm{Bi}$-added $\mathrm{Ba}_{4} \mathrm{Nd}_{9+1 / 3} \mathrm{Ti}_{18} \mathrm{O}_{54}$ solid solutions. Jpn J Appl Phys 2000, 39: 5645-5649.
[14] Thomas S, Deepub V, Uma S, et al. Preparation, characterization and properties of $\mathrm{Sm}_{2} \mathrm{Si}_{2} \mathrm{O}_{7}$ loaded polymer composites for microelectronic applications. Mat Sci Eng B 2009, 163: 67-75.

[15] Subodh G, Deepu V, Mohanan P, et al. Dielectric response of high permittivity polymer ceramic composite with low loss tangent. Appl Phys Lett 2009, 95: 062903.

[16] Wu C-C, Yang C-F, Chen Y-C, et al. Fabrication of circular polarization antenna on $\mathrm{PEI} / \mathrm{BSTZ}$ composite substrate for the application of UHF-RFID reader. $J$ Electrochem Soc 2009, 156: G197-G200.

[17] Hao HG, Lu HX, Chen W, et al. A novel miniature microstrip antenna for GPS applications. In Informatics in Control, Automation and Robotics. Yang D, Ed. Springer Berlin Heidelberg, 2011: 139-147.

Open Access The articles published in this journal are distributed under the terms of the Creative Commons Attribution 4.0 International License (http://creativecommons. org/licenses/by/4.0/), which permits unrestricted use, distribution, and reproduction in any medium, provided you give appropriate credit to the original author(s) and the source, provide a link to the Creative Commons license, and indicate if changes were made. 